\title{
MODELOS ORGANIZADORES DO PENSAMENTO: UMA PERSPECTIVA DE PESQUISA SOBRE O RACIOCÍNIO MORAL COM ADOLESCENTES AUTORES DE INFRAÇÃO
}

Leonardo Lemos de Souza* Mário Sérgio Vasconcelos

\begin{abstract}
RESUMO. Este artigo tem como propósito ampliar as perspectivas de investigação no campo da moralidade. Mais especificamente, apresentamos uma proposta para o estudo da moralidade de adolescentes autores de infração, utilizando o referencial teórico=metodológico da Teoria dos Modelos Organizadores do Pensamento. Buscamos, através da idéia de complexidade, compreender o funcionamento cognitivo na elaboração de raciocínios morais diante de situações de conflito. Com essa perspectiva, fizemos uma investigação que teve por objetivo identificar os modelos organizadores aplicados na resolução de conflitos morais hipotéticos por 20 adolescentes masculinos autores de infração que cumprem medida socioeducativa. Através de entrevistas, narramos uma situação de conflito moral envolvendo uma relação de amizade, agressão física e roubo. Foram identificados 10 modelos organizadores, os quais foram agrupados em 3 categorias. Tais modelos refletiram a diversidade e as regularidades presentes nos raciocínios elaborados para resolver os conflitos apresentados. Concluiu-se que a variedade dos modelos organizadores identificados evidencia a importância dos conteúdos na construção dos raciocínios morais.
\end{abstract}

Palavras-chave: raciocínio moral; adolescentes autores de infração; modelos organizadores do pensamento.

\section{ORGANIZING MODELS OF THINKING: A RESEARCH ABOUT MORAL REASONING WITH TRANSGRESSOR ADOLESCENTS}

\begin{abstract}
This article has the aim to expand the perspective of research in the field of morality. We present a proposal of morality study of outlaw teenagers according to Thinking Organizer Models Theory. Through the idea of complexity we search to understand the cognitive process in the elaboration of moral reasoning inside situations of conflict. With this perspective, we developed a research that aimed to identify which organizer models were applied by 20 outlaw male teenagers who abide by social punishment to solve the hypothetical moral conflicts. Through interviews we told them a situation of moral conflict that involved friendship relation, physical aggression and steal. We could identified several models which were joined in three categories. Such models reflected the diversity and regularity that are present inside the elaborated reasoning to solve the conflicts shown by us. We conclude that the diversity of organizer models identified shows the importance of the contents in the construction of moral reasoning.
\end{abstract}

Key words: moral reasoning; outlaw teenagers; thinking organizer models.

Nas últimas décadas tem aumentado, no Brasil, o fenômeno da violência entre as crianças e os adolescentes. Para que se possa ter uma idéia da dimensão do problema, em 1989 foram julgados 11.967 processos envolvendo adolescentes e crianças, apenas na capital paulista e, só no primeiro semestre de 1999, foram 9.892 casos (Varas Especiais da Infância e da Juventude SP/OESP, 1999 citado por
Conselho Regional de Psicologia, 6 ª Região, 1999). A violência cometida por adolescentes também tornou-se tema freqüente na mídia, em filmes e debates realizados por diferentes instituições governamentais e não-governamentais. O tema tem gerado polêmicas em torno das ações preventivas e remediativas para sanar o problema. Um exemplo disso é o debate em torno do rebaixamento da idade penal de 18 para 16 anos.

* Doutorando em Educação pela UNICAMP, Mestre em Psicologia pela UNESP-Assis. Professor do Curso de Psicologia da UNIP e Professor Substituto no Curso de Psicologia da Unesp/Campus de Assis.

\# Doutor em Psicologia Escolar e do Desenvolvimento Humano pela USP-SP e Pós-Doutorado na Universidade de Barcelona/Espanha. Professor do Curso de Psicologia da Unesp/Campus de Assis. 
Pesquisas que buscam explicações para o fenômeno da violência também constataram o aumento de infrações cometidas por adolescentes, porém apontam novas tendências. Volpi (1999) e Adorno (2000) destacam em suas investigações o aumento de infrações, mas não um aumento significativo das infrações consideradas violentas pela legislação. Adorno (2000) apresenta dados que revelam que, na última década, os crimes violentos cometidos por adolescentes não são a maioria, quando comparados com os cometidos pelos adultos e com outros crimes. Na década de 1980, 37\% dos crimes cometidos por adolescentes eram violentos, contra 63\% de não-violentos. Já na década de 1990, 20\% eram crimes violentos, contra $80 \%$ de não-violentos. Esses dados não significam que a violência não tenha aumentado, porém apontam para um quadro mais transparente e para mudanças nas transgressões cometidas por adolescentes.

Dado esse quadro de violência, são diversas as tentativas de compreender melhor o adolescente autor de infrações. Com essa intenção, voltamo-nos para as investigações sobre os raciocínios morais desses adolescentes, isto é, sobre o que pensam e como pensam diante de situações que envolvem problemas morais.

\section{ESTUDOS SOBRE O RACIOCÍNIO MORAL DO ADOLESCENTE AUTOR DE INFRAÇÃO}

As pesquisas sobre o desenvolvimento moral de adolescentes autores de infração têm várias perspectivas de análise. Para conhecermos melhor as linhas teóricas que se destacam nas investigações sobre o raciocínio moral de adolescentes autores de infração, realizamos um levantamento bibliográfico acerca dos estudos realizados no Brasil e no exterior.

$\mathrm{Na}$ base de dados da American Psychological Association (APA), referentes ao período que vai desde a década de 1970 até o ano de 2001, encontramos 77 pesquisas sobre o tema "desenvolvimento moral e adolescentes autores de infração". Produzidas em vários países, podem ser agrupadas conforme os seguintes objetivos: a) investigar os níveis de desenvolvimento moral dos adolescentes autores de infração; b) relacionar os níveis de desenvolvimento moral aos tipos de interação na escola, na família e internatos; c) promover o desenvolvimento do raciocínio moral desses adolescentes a partir de grupos de discussão, de atividades cooperativas e comunitárias; e d) construir instrumentos de prevenção de violência nas escolas e nos grupos de adolescentes.
Nesses estudos, destacam-se, principalmente, três tendências teóricas. A maior parte tem como referência a perspectiva cognitivo-evolutiva de Lawrence Kohlberg, baseando-se nos níveis evolutivos descritos por esse autor e nas suas propostas de educação moral. Outra perspectiva refere-se à moral pró-social de Nancy Eisenberg, que tem como objetivo analisar o desenvolvimento da moral através do raciocínio sobre situações que envolvem atitudes altruístas e de colaboração com o outro (Eisenberg, 1979). Com esse enfoque, aparecem pesquisas sobre a eficiência de ações preventivas nas escolas e em outros espaços de interação do adolescente e do adolescente autor de infração (por exemplo: Carlo, Eisenberg \& Koller, 1998). Também aparecem, com freqüência, análises da moralidade sob a perspectiva psicanalítica. Estas buscam compreender a constituição egóica dos sujeitos e sua relação com a transgressão e a violência (por exemplo: Al-Falai, 1992.)

No Brasil, dentre os estudos sobre o desenvolvimento moral do adolescente autor de infração, encontramos apenas os que foram desenvolvidos por Bzuneck (1979), Koller (1989), Menin (2000) e Guará (2000) ${ }^{1}$.

Bzuneck (1979), ao realizar um estudo sobre a moralidade de adolescentes infratores e não-infratores, procurou verificar se existia diferença entre o nível de julgamento moral apresentado por estes dois grupos. Buscou, ainda, identificar se existia influência da ausência paterna nos níveis apresentados por eles. Assim, selecionou sujeitos provenientes de famílias "intactas" e famílias que considerou desfeitas (pela ausência do pai) e comparou os níveis de julgamento moral considerando as variáveis sexo, idade, nível de escolaridade e nível socioeconômico. Com base nas idéias de Kohlberg e a partir da análise das respostas dadas pelos sujeitos, Bzuneck pôde constatar que a maioria da população de infratores pesquisada tem níveis de julgamento inferiores (pré-convencional estágio 2) aos de adolescentes não infratores (convencional - estágio 3).

Já Koller (1989), com o objetivo de verificar se existia diferença entre os níveis de julgamento moral dos adolescentes infratores e não infratores

\footnotetext{
Procedemos ao levantamento dos trabalhos relacionados à moralidade do adolescente infrator nas bases de dados eletrônicas da USP, Unicamp, UFRGS e PsycLIT, complementando as informações conseguidas na base de dados da APA (PsycoINFO). Encontramos várias pesquisas que fazem referência a adolescentes em situação de risco, mas apenas essas quatro tratam diretamente do tema do infrator e moralidade.
} 
institucionalizados (internos em programas de assistência social), aplicou o Moral Judgement Intervew (Entrevista de Julgamento Moral), de Kohlberg, em 40 sujeitos nessas condições, de nível socioeconômico baixo, com idade média de 16 anos e que cursavam o ensino fundamental. Desses, 20 (10 meninas e 10 meninos) eram infratores e 20 (10 meninos e 10 meninas) eram não-infratores, em situação de orfandade. Os resultados que obteve são semelhantes aos de Bzuneck (1979) e de outras amostras americanas. Os dados mostraram que os adolescentes não-infratores tinham nível de desenvolvimento mais alto que o dos infratores, sendo que a maioria encontrava-se no estágio 2 - da moralidade pré-convencional.

Os resultados e o referencial utilizado nessas pesquisas levam a entender que o nível de desenvolvimento moral dos adolescentes autores de infração está situado no estágio-2 do nível préconvencional kohlberguiano. Esse estágio se define pela moralidade que se orienta pelo individualismo com finalidade instrumental. $\mathrm{O}$ sujeito que se encontra nesse estágio considera válida ou correta a regra ou a lei que traz favorecimento para si ou para outrem, ou ainda, que resulte numa compensação ou numa troca. O comprometimento com os valores de um grupo ou de uma sociedade somente é efetivado se dentro desses parâmetros de julgamento. Para essa linha de análise, o desenvolvimento cognitivo do adolescente que se encontra nesse estágio se encontraria nos níveis mais baixos, próximo de um nível operatório concreto, em cujas ações ainda predominaria o pensamento egocêntrico.

Não obstante, críticas voltadas sobre essa perspectiva de análise salientam que o desenvolvimento do raciocínio moral não pode ser descrito apenas alicerçado nos recursos operatórios e/ou analisado exclusivamente num princípio ou valor como a justiça (Sastre \& Moreno, 2000; Arantes, 2000). Assim, dependendo da situação e dos conteúdos envolvidos, as representações dos sujeitos variam, sendo menos ou mais complexas. Nesse sentido, a vertente utilizada por Bzuneck e Koller nos parece incompleta para o estudo dos pensamentos ou raciocínios morais.

A ampliação do conceito de moral que vem sendo realizada no campo da Psicologia Moral e as discussões sobre a formulação de raciocínios nos levam a outras perspectivas de análise, que dão maior relevância aos conteúdos. Nesta direção situam-se as pesquisas de Menin (2000) e Guará (2000). Menin (2000), procurando novas possibilidades de investigação no campo da psicologia moral, realizou um estudo das representações sociais de justiça de adolescentes infratores, no qual testou diferentes instrumentos de coleta de informações. Elegeu o referencial das representações sociais (Moscovic citado por Menin, 2000), pois considerou que, para abordar temas morais como concepções de justiça, é necessário avançar em relação à prática de pesquisa que envolve os estágios e que impossibilita encontrar a diversidade de pensamento em diferentes grupos sociais. Segundo Menin, as representações são uma forma de conhecimento que resulta das experiências e das relações do indivíduo e de grupos; portanto, um conhecimento socialmente elaborado, ligado a uma determinada realidade e que influencia os comportamentos. Como instrumentos, Menin utilizou questões, associações livres e histórias sobre temas envolvendo a justiça, como a origem e a mutabilidade de leis, o conhecimento de instituições ligadas à justiça e situações consideradas como injustas. Nos resultados apontou o aparecimento de respostas que apresentaram tendências para princípios de igualdade, liberdade e respeito mútuo consideradas universais. No entanto, não encontrou uma "lógica" nas respostas dos adolescentes às questões colocadas. Assim, os julgamentos dos adolescentes podiam ser "pré-convencionais para questões mais abertas, como associações livres, convencionais para outras mais estruturadas, autônomos em questões que pedem idealizações e heterônomos noutras mais ligadas à realidade." (Menin, 2000, p. 16).

Guará (2000), por sua vez, empreendeu uma investigação com adolescentes autores de infração internos da FEBEM, baseada nas idéias de Lawrence Kohlberg, Jean Piaget e Agnes Heller, estabelecendo uma relação entre a moralidade desses adolescentes e o seu cotidiano. Utilizou vários instrumentos, como entrevistas com grupos para discussão de dilemas morais hipotéticos e dilemas reais vividos ou vicários, além de entrevistas individuais sobre temas ligados ao cotidiano desse adolescente (escola, família, trabalho, grupo de amigos e a FEBEM). Não utilizou para sua análise os métodos de avaliação descritos por Kohlberg, embora tenha trabalhado com os estágios como categorias prévias, encontrando, na maioria dos adolescentes, níveis pré-convencionais. Encontrou, porém, outros valores, como de lealdade, humildade, honestidade e liberdade, nos temas e nas argumentações dos adolescentes sobre os dilemas reais e vicários. 
Os estudos de Menin (2000) e Guará (2000), ao procederem a uma análise em que buscam as modalidades de raciocínio dos adolescentes diante de temas e situações de conflito moral, ressaltam a emergência de conteúdos desconsiderados numa análise que tem como referência apenas os recursos operatórios.

Coerente com essa linha de investigação, que sugere a complexidade e a diversidade dos raciocínios na resolução de conflitos morais, estão as pesquisas de Gilligan (1993), Damon (1995) e Blasi (1995). Nessa mesma direção se encontra a Teoria dos Modelos Organizadores do Pensamento, elaborada por Montserrat Moreno, Genoveva Sastre e Aurora Leal, a qual considera em sua proposta, além dos recursos operatórios, a importância dos conteúdos na formulação de raciocínios morais (Moreno, Sastre, Leal \& Bovet, 1999).

\section{MODELOS ORGANIZADORES DO PENSAMENTO}

A crítica às ciências clássicas sugere a reformulação de suas bases na direção de uma ciência que avance da regularidade para a complexidade ${ }^{2}$. Questionamentos dessa natureza já foram anunciados por algumas ciências, como a Física e a Biologia, diante da impossibilidade de explicar fenômenos com base no pensamento tradicional científico. $\mathrm{Na}$ Psicologia, os fenômenos psicológicos, notadamente os da cognição, foram estudados quase exclusivamente pela via da regularidade, muitas vezes sendo considerados como verdade e como naturais. No entanto, já sabemos que esse caminho é insuficiente e que o fenômeno psicológico tem várias faces. É necessário, também, trilhar o caminho da diversidade e da complexidade e, uma vez descrita a regularidade, buscarmos as explicações na mudança (Moreno \& col., 1999).

Desde quando a Psicologia passou a estudar o ser humano enquanto sujeito que evolui, incluiu na esfera psicológica a idéia de mudança. Mas em toda mudança há algo que permanece, e a conjunção da permanência e da mudança aumenta a complexidade dos novos fenômenos que se vislumbram, "urgindo a necessidade de modelos capazes de descrever e interpretar simultaneamente o que permanece e o que muda, isto é, capazes de dar conta da complexidade" (Moreno \& col., 1999, p.16-17). Dentro do paradigma

2 Morin (2000) resgata essa idéia a partir da etimologia da palavra complexo que é complexus: o que é tecido junto. da complexidade é que está a raiz da Teoria dos Modelos Organizadores.

\section{Organização dos modelos: dados, significados e implicações}

A complexidade dos modelos organizadores pressupõe relações entre estrutura e conteúdo e é composta pela realidade objetiva e subjetiva construída pelo sujeito. Segundo Moreno e col. (1999), os modelos são elaborados na interação do indivíduo com o meio, que atua como um regulador da atividade cognitiva. O sujeito - ativo nesse processo assimila os dados de uma situação concreta e atribui significado e uma função a eles, construindo um modelo para explicar a situação. Um modelo é definido como:

o conjunto de representações que o sujeito realiza a partir de uma situação determinada, constituído pelos elementos que abstrai e retém como significativos entre todos os possíveis, aqueles que imagina ou infere como necessários, os significados e as implicações que lhes atribui, e as relações que estabelece entre todos eles. Os modelos organizadores do pensamento constituem aquilo que é tido por cada sujeito como a realidade, a partir da qual elabora pautas de conduta, explicações ou teorias (Sastre, Moreno \& Fernandez, citados por Arantes, 2000, p.142).

A seleção que o sujeito realiza dos fatos ou dos objetos perceptíveis são os dados ou elementos de um modelo organizador. Esses elementos têm sua origem: a) nas abstrações que o sujeito faz dos fatos observáveis; b) nas inferências que faz sobre a situação com as quais se depara ou, ainda, c) na invenção de outros dados, em função da necessidade de compreensão da situação observada (Moreno \& col., 1999).

O contexto de experiência é fundamental no processo de seleção de dados de uma situação observada. Não são retidos todos os dados possíveis a respeito da situação; somente aqueles a que se atribui significado e que podem ser relacionados entre si mediante uma organização. Isto também não quer dizer que o sujeito desconheça os outros dados da situação, somente que não são considerados como representativos dela. Distinguir uma propriedade ou abstrair um dado de determinado objeto ou de uma situação é diferenciá-lo do conjunto de dados presentes - o que traz implícita uma atribuição de significado. O processo de abstração de um dado traz consigo a sua significação. 
Além disso, os modelos organizadores também têm implicações que servem de base para a explicação de fatos e para a ação:

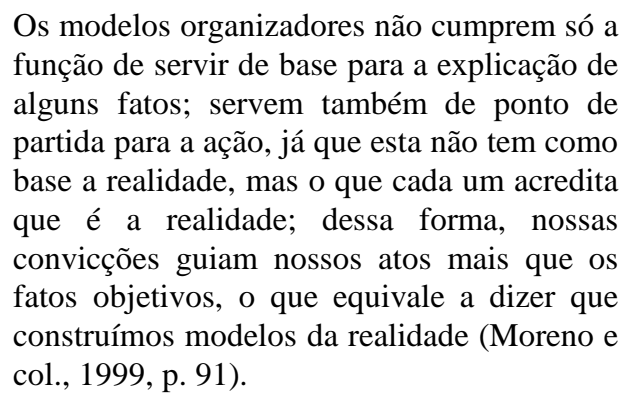

As implicações dos significados atribuídos aos dados são conseqüências desse processo organizador. As relações entre elementos, significados e implicações retratam o modelo e sua complexidade, pois indicam a diversidade $\mathrm{e}$ as regularidades presentes na realidade elaborada pelo sujeito.

Assim sendo, a perspectiva dos Modelos Organizadores nos parece promissora, pelos seguintes motivos:

a) no estudo do fenômeno psicológico, expressa a organização entre dados, significados e suas implicações;

b) expressa a conjugação entre estrutura e conteúdos, permitindo, assim, uma apreensão mais abrangente da complexidade do modo como o sujeito pensa a realidade, já que apenas os recursos operatórios não são suficientes para explicar o funcionamento cognitivo. Incluem-se nas operações empregadas os valores, os sentimentos, os princípios e as regras envolvidos no raciocínio;

c) permite observar a diversidade dos modelos de realidade;

d) permite observar as regularidades entre os modelos de realidade;

e) numa investigação, não estabelece previamente a classificação das respostas dos sujeitos. Desse modo confere uma melhor fidedignidade aos dados coletados, demonstrando, com mais detalhes, seu papel no funcionamento cognitivo;

f) representa um avanço metodológico significativo no campo da psicologia voltada para a análise de conteúdos;

g) no campo da moralidade avança, notadamente, na análise de situações envolvendo conflitos. Ao estudarmos, como no caso da investigação que apresentaremos a seguir, o raciocínio de adolescentes autores de infração, pudemos buscar, através da análise de conflitos referente às infrações, os conteúdos que organizam suas representações e, assim, compreender melhor a realidade subjetiva dos sujeitos.

\section{MODELOS ORGANIZADORES NA RESOLUÇÃO DE CONFLITOS MORAIS: UM ESTUDO COM ADOLESCENTES AUTORES DE INFRAÇÃO}

\section{A investigação}

A pesquisa apresentada em seguida teve como objetivo investigar os modelos organizadores aplicados por adolescentes autores de infração na resolução de conflitos morais, envolvendo uma situação de roubo e agressão ${ }^{3}$. Mais especificamente, buscamos:

- verificar os modelos que eles constroem sobre roubo e agressão;

- verificar se existe diversidade entre os modelos construídos pelos participantes e

- verificar se existem regularidades entre os modelos construídos pelos participantes.

Foram investigados os modelos organizadores aplicados por vinte adolescentes autores de infração, todos do sexo masculino e com idade entre 13 e 18 anos, de nível socioeconômico baixo (classes C e D) ${ }^{4}$. Esses participantes faziam parte de programas scioeducativos, que executam medidas socioeducativas (Liberdade Assistida e Prestação de Serviços à Comunidade), promovidos por prefeituras de dois municípios do interior do Estado de São Paulo.

Realizamos uma entrevista na qual apresentamos aos participantes uma situação de conflito que envolvia uma relação entre amigos na situação de roubo e agressão. As entrevistas foram realizadas individualmente e o seu conteúdo foi transcrito no local.

A situação apresentada aborda uma relação interpessoal entre amigos, porque a relação de amizade está presente na maioria dos conflitos relatados por

\footnotetext{
Limitamos essa pesquisa aos juízos morais e não a estendemos às ações concretas dos adolescentes. Também não foi nosso objetivo fazer um estudo evolutivo dos modelos detectados. Tal objetivo será matéria de uma próxima pesquisa.

4 Essas informações foram obtidas a partir da aplicação do questionário e critérios de classificação de níveis socioeconômicos proposta pela ABIPEME (Associação Brasileira de Institutos de Pesquisa de Mercado). A escala da ABIPEME (1978) é um instrumento reconhecido e utilizado para que, através de análise de itens de consumo e grau de escolaridade do responsável pela família, se possa caracterizar as classes A, B, C, D e E.
} 
adolescentes em pesquisas anteriores que levantaram os dilemas e conflitos morais vividos por eles e por pessoas próximas (Guará, 2000; Oliveira \& Costa, 1995 e 1997). ${ }^{5}$ Além disso, as infrações mencionadas no conflito proposto estão presentes no cotidiano desses adolescentes. $\mathrm{O}$ roubo $^{6}$ e a agressão física são transgressões que aparecem entre as mais cometidas por adolescentes (ver, por exemplo, Volpi, 1999) e as que mais aparecem na amostra entrevistada (14 roubos/furtos e 8 agressões, de um total de 26 infrações).

Desse modo, a situação de conflito apresentada envolve o tema da agressão física cometida por um amigo do protagonista do conflito diante de uma tentativa de roubo. A situação é:

Caio e João eram amigos e estavam saindo de uma festa quando Caio viu que um rapaz estava tentando roubar sua moto. Caio começou uma briga com o rapaz e bateu nele com um bastão. João presenciou tudo.

Solicitamos, então, aos participantes que respondessem às seguintes questões:

1) O que João pensou nesse momento? Explique detalhadamente sua resposta

2) O que ele poderia fazer para ser justo? Explique detalhadamente sua resposta

A primeira das questões sugeridas em nossas entrevistas sobre a situação de conflito construída solicitou do entrevistado um juízo de realidade, ao responder o que pensou o protagonista da situação. Desse modo, com a intenção de verificar a extensão dos conteúdos presentes nas representações, formulamos uma pergunta aberta, que não remete de forma direta e explícita a possíveis ações do sujeito. Estivemos atentos em detectar se os dados construídos pelos sujeitos (e os significados e as implicações inerentes aos dados) estavam presentes no conflito apresentado ou se foram incluídos pelo participantes como elementos significativos.

A questão seguinte exigia do sujeito um juízo de valor moral, ao pedir-lhe que respondesse o que se

5 Por esse motivo, não foi nosso objetivo verificar a presença ou não das relações de amizade nos modelos organizadores. Para isso, teríamos que elaborar um estudo comparativo com um conflito envolvendo situação de inimizade.

6 Utilizamos o termo roubo em vez de furto na situação narrada, pois as diferenças demarcadas pela terminologia jurídica muitas vezes não estão claras para os adolescentes. $\mathrm{O}$ termo roubo parece mais popular do que furto para definir posse de coisa alheia (seja com ou sem violência). poderia fazer para ser justo diante da situação de conflito. Nesse caso, por se tratar de uma pergunta indicativa de uma ação que implica uma forma de proceder diante da situação, estivemos atentos às ações que remetem a uma avaliação moral pautada nas representações do sujeito sobre o que é ser justo.

\section{Os modelos organizadores}

A partir das entrevistas, analisamos 20 protocolos de respostas em cada questão, o que resultou num total de 40 protocolos de respostas elaboradas pelos 20 participantes da pesquisa.

Apresentamos, a seguir, em quadros, os modelos organizadores identificados nas questões 1 e 2. No total foram 10 modelos organizadores. No processo de "extração" dos conteúdos, buscamos a organização dos modelos através da análise das relações entre os dados que foram destacados e/ou criados pelos sujeitos, seus significados e as implicações dos raciocínios emitidos. Após a descrição dos modelos organizadores, analisamos os resultados obtidos na questão 1 e na questão 2 , e identificamos, conforme nossos objetivos, categorias nas quais se enquadram tais modelos (as categorias serão descritas mais adiante). Elencar os modelos e as categorias teve como propósito metodológico:

- verificar a diversidade dos modelos na situação; para isso fizemos um levantamento da freqüência de aplicação dos modelos em cada questão;

- verificar a regularidade dos modelos na situação; para isso, a partir da definição dos modelos, identificamos as categorias nas quais se enquadram os modelos.

\section{Apresentação dos modelos organizadores}

Identificamos cinco modelos organizadores (1, 2, 3,4 e 5) referentes à questão 1 , e cinco modelos $(1,2$, 3,4 e 5) referentes à questão 2 .

\section{Apresentação dos modelos organizadores relativos à questão 1}

QUESTÃO 1 (O que João pensou nesse momento?)

\section{MODELO 1:}

\begin{tabular}{|l|l|}
\hline Dados abstraídos e retidos como significativos & Significados atribuídos aos dados \\
\hline - Papel do João & • Ajudar a impedir o roubo \\
\hline - Agressão & • Necessária para impedir o roubo \\
\hline - Roubo & • É errado \\
\hline $\begin{array}{l}\text { Implicaçães elou relaçães entre dados e significados: } \\
\text { João entra na briga com Caio porque precisa de sua ajuda para impedir o roubo. }\end{array}$
\end{tabular}


Nesse modelo, os dados retidos como significativos foram o papel de João, a agressão e o roubo. A agressão e o roubo figuravam dentre os conteúdos apresentados na situação de conflito apresentada e o papel de João, não. O significado atribuído à agressão é que é necessária para impedir o roubo. O significado do roubo é errado. O papel de João significa ajudar a impedir o roubo. As implicações e/ou relações entre dados e significados nesse modelo são que João entra na briga ao lado de Caio porque este precisa de sua ajuda para impedir o roubo.

Exemplo de resposta nas quais pudemos identificar o modelo 1 :

Ex.: "Ele deveria ajudar a bater no cara porque tava roubando a moto." (ORS, 15 anos e 7 meses) ${ }^{7}$.

\section{MODELO 2:}

\begin{tabular}{|l|l|}
\hline $\begin{array}{l}\text { Dados abstraídos e retidos como } \\
\text { significativos }\end{array}$ & Significados atribuídos aos dados \\
\hline - Papel do João & $\begin{array}{l}\text { - Separar; não ferir o rapaz; proteger } \\
\text { para Caio ano ir preso }\end{array}$ \\
\hline - Agressão & - Errada \\
\hline $\begin{array}{l}\text { Implicações e/ou relaçães entre dados e significados: } \\
\text { João impede a briga, separando-os, porque a agressão é errada e Caio pode ir } \\
\text { preso se ferir o rapaz. }\end{array}$ \\
\hline
\end{tabular}

Diferentemente do modelo 1, o dado papel do João, que não estava explícito na situação nem no enunciado da questão, teve como significados atribuídos: separar, não ferir o rapaz e proteger Caio de ir preso. O outro dado destacado estava presente na situação, mas teve como significado que agredir é errado. A implicação estabelecida pelos adolescentes entre esses dados e significados resultou na resolução do conflito impedindo a briga, separando-os, porque a agressão é errada e poderia ir preso se ferisse o rapaz.

Exemplo de respostas desse modelo:

Ex.: "Separava o amigo do cara. Porque o amigo [Caio] não tava certo e tinha que ver o lado do rapaz. Então ele separaria para não ter problema, até para o amigo que podia ser preso." (LDP, 18 anos e 3 meses).

7 A elaboração dos modelos teve por base as várias respostas e explicações presentes nos protocolos. Em função da grande quantidade de respostas coletadas, estamos exemplificando com apenas uma, representativa do modelo construído.
MODELO 3:

\begin{tabular}{|l|l|}
\hline Dados abstraídos e retidos como significativos & Significados atribuídos aos dados \\
\hline - Agressão & - Errada \\
\hline - Papel do Caio & - Solicitar a ajuda da polícia \\
\hline - Papel da polícia & - Impedir o roubo; prender \\
\hline $\begin{array}{l}\text { Implicações elou relações entre dados e significados: } \\
\text { Caio deveria chamar a polícia e não agredir, ela pode resolver o caso do roubo } \\
\text { prendendo o rapaz. }\end{array}$ \\
\hline
\end{tabular}

Como dado não presente diretamente no conflito destaca-se o papel de Caio, que significa solicitar a ajuda da polícia, e o papel da polícia, que significa impedir o roubo e prender o rapaz. Como dado presente no contexto, os adolescentes abstraíram a agressão, que foi considerada como errada. As relações entre dados e significados nesse tipo do raciocínio empregado no modelo revelam que a solução da situação de conflito seria Caio chamar a polícia e não agredir; a polícia pode resolver o caso do roubo, prendendo o rapaz.

Exemplo de resposta em que identificamos o modelo 3:

Ex.: "Podia ter chamado a polícia por causa que tinha que entregar o cara que roubou. Ele não precisava ter batido, era só chamar a polícia." (WAR, 16 anos e 3 meses).

\section{MODELO 4:}

\begin{tabular}{|l|l|}
\hline $\begin{array}{l}\text { Dados abstraídos e retidos como } \\
\text { significativos }\end{array}$ & Significados atribuídos aos dados \\
\hline - Papel do João & $\begin{array}{l}\text { Encaminhar o problema do roubo à } \\
\text { polícia }\end{array}$ \\
\hline - Não-agressão & Medo de ser agredido \\
\hline - Papel da polícia & - Impedir o roubo; prender o rapaz \\
\hline $\begin{array}{l}\text { Implicações e/ou relações entre dados e significados: } \\
\text { João não se envolve na briga por medo e encaminha o problema do roubo à } \\
\text { polícia que deve prender o rapaz. }\end{array}$
\end{tabular}

Nesse modelo, os três dados abstraídos não estavam presentes na situação. O papel do João significou encaminhar o problema à polícia. $\mathrm{O}$ dado papel da polícia significou prender o rapaz. Como novidade aparece o dado da não-agressão de João em função do sentimento de medo de ser agredido. As relações entre os dados abstraídos e retidos como significativos e seus significados implicam em uma solução da situação em que João não se envolve na briga por medo de sofrer agressão e encaminha o problema do roubo à polícia, que deve prender o rapaz.

Exemplo de resposta do participante que aplicou o modelo 4 na questão 1 : 
Ex.: "Chamar a polícia. Ele [João] não vai entrar no meio da briga com bandido, vai que se ferra.". (DAA, 17 anos e 4 meses) ${ }^{8}$.

\section{MODELO 5:}

\begin{tabular}{|l|l|}
\hline $\begin{array}{l}\text { Dados abstraídos e retidos como } \\
\text { significativos }\end{array}$ & Significados atribuídos aos dados \\
\hline - Papel de João & $\begin{array}{l}\text { - Separar; não ferir o rapaz; encaminhar } \\
\text { o problema do roubo à polícia }\end{array}$ \\
\hline - Papel da polícia & - Impedir o roubo; prender o rapaz \\
\hline - Agressão & - Errada \\
\hline - Roubo & - Errado \\
\hline $\begin{array}{l}\text { Implicações e/ou relações entre dados e significados: } \\
\text { João pensou que separar os dois é o melhor para não ferir o rapaz e, ele mesmo, } \\
\text { encaminhar o problema do roubo à polícia. }\end{array}$ \\
\hline
\end{tabular}

Entre os dados abstraídos da situação de conflito que não são explicitados na situação estão o papel de João e o papel da polícia. Os significados atribuídos ao papel de João são o de encaminhar à polícia a solução do roubo e separar os dois para não ferir o rapaz. Ao dado papel da polícia o significado foi o de impedir o roubo e prender o rapaz. Os dados explicitados na situação que foram retidos no modelo foram a agressão e o roubar, considerados errados. Sobre as implicações, os sujeitos remeteram a resolução do conflito à ação de João e da polícia, sendo que o primeiro separa os dois, para não ferir o rapaz e encaminha o problema do roubo à polícia.

Exemplo de respostas que aplicam o modelo 5:

Ex.: "Tentava resolver isso numa boa. Evitar a briga, separar os dois e chamava a polícia para não brigarem, sem violência". (ADA, 18 anos e 9 meses).

Apresentação dos modelos organizadores relativos à questão 2

QUESTÃO 2 (O que ele poderia fazer para ser justo?)

Como afirmamos, a questão 2 exigia do sujeito um juízo de valor, ao pedir-lhe que respondesse o que se poderia fazer diante da situação de conflito para ser justo. Nesse caso, por se tratar de uma pergunta indicativa de uma ação que implica no papel de João (ausente na situação de conflito apresentada) e numa forma de proceder moralmente diante da situação, estivemos atentos às respostas que remetem à avaliação moral, pautada nas representações do sujeito sobre o que é ser justo. Por esse motivo, não apresentaremos, a seguir, considerações sobre a presença ou ausência dos dados abstraídos no conflito apresentado.

\footnotetext{
8 Somente um sujeito aplicou o modelo 4 na questão 1.
}

MODELO 1:

\begin{tabular}{|c|c|}
\hline Dados abstraídos e retidos como significativos & Significados atribuídos aos dados \\
\hline - Papel do João & - Aconselhar (Caio); conversar \\
\hline - Agressão & - Errada \\
\hline
\end{tabular}

O dados abstraídos foram o papel do João, que significava aconselhar Caio e conversar com ele, e a agressão, que foi considerada errada. Os raciocínios dos adolescentes implicaram que João seria justo impedindo a agressão e aconselhando Caio, esclarecendo que é errada.

Exemplo das respostas em que os adolescentes aplicaram o modelo 1:

Ex.: "Poderia chegar e dar conselhos porque ele (Caio) não podia ter feito isso, bater no cara." (FSS, 15 anos e 7 meses).

\section{MODELO 2:}

\begin{tabular}{|l|l|}
\hline Dados abstraídos e retidos como significativos & Significados atribuídos aos dados \\
\hline - Papel do João & $\begin{array}{l}\text { - Separar a briga para aconselhar } \\
\text { (Caio); conversar }\end{array}$ \\
\hline - Agressão & - Errada; compreensível \\
\hline - Roubo & $\begin{array}{l}\text { Errado; solicita compreensão, } \\
\text { saber seus motivos }\end{array}$ \\
\hline $\begin{array}{l}\text { Implicações e/ou relações entre dados e significados: } \\
\text { João deve impedir a agressão aconselhando Caio e conversar com o rapaz para } \\
\text { tentar compreender os motivos do roubo. }\end{array}$ \\
\hline
\end{tabular}

Ao dado sobre o papel de João é atribuído significado semelhante ao do modelo anterior, que é o de aconselhar; conversar. À agressão é atribuído, além do significado de errada, o de que é compreensivel. O roubo teve como significado que é errado e que necessita de compreensão para se saber sobre seus motivos. O que está explícito no raciocínio dos sujeitos que aplicaram esse modelo é que a solução mais justa que João podia concretizar era impedir a agressão aconselhando Caio e conversar com o rapaz para tentar compreender as razões do roubo.

Exemplo das respostas em que identificamos o modelo 2:

Ex.: "O roubo é errado, mas tem que separar a briga porque tem que conversar (sobre) porque o cara queria a moto, tinha que saber." (VTN, 13 anos e 4 meses).

\section{MODELO 3:}

\begin{tabular}{|c|c|}
\hline Dados abstraídos e retidos como significativos & Significados atribuídos aos dados \\
\hline - Papel do João & $\begin{array}{l}\text { Encaminhar o problema do } \\
\text { roubo à polícia }\end{array}$ \\
\hline - Papel da polícia & - Resolver o roubo; prender o rapaz \\
\hline - Roubo & - Errado \\
\hline \multicolumn{2}{|c|}{$\begin{array}{l}\text { Implicações e/ou relações entre dados e significados: } \\
\text { João deve encaminhar o problema do roubo à polícia que deve resolvê-lo } \\
\text { prendendo o rapaz. }\end{array}$} \\
\hline
\end{tabular}


O papel de João teve como significado encaminhar o problema do roubo à polícia. Ao papel da polícia foram atribuídos os significados de impedir o roubo e prender o rapaz. Ao roubo foi atribuído o significado de ser errado. A ação para João se considerar justo está refletida no resultado de que João deve encaminhar o problema do roubo à polícia, que deve resolvê-lo prendendo o rapaz.

Exemplo de respostas nas quais identificamos o modelo 3:

Ex.: "Ligar para a polícia é o mais justo, ela pode resolver o caso do roubo". (DAA, 16 anos).

\section{MODELO 4:}

\begin{tabular}{|l|l|}
\hline $\begin{array}{l}\text { Dados abstraídos e retidos como } \\
\text { significativos }\end{array}$ & Significados atribuídos aos dados \\
\hline - Papel de João & $\begin{array}{l}\text { - Aconselhar (Caio); conversar; encaminhar o } \\
\text { problema do roubo à polícia }\end{array}$ \\
\hline - Papel da polícia & - Resolver o roubo; prender o rapaz \\
\hline - Agressão & Errada \\
\hline - Roubo & - Errado \\
\hline $\begin{array}{l}\text { Implicaçães e/ou relações entre dados e significados: } \\
\text { João deve impedir a agressão aconselhando Caio, esclarecendo que é errada e } \\
\text { encaminhar à polícia a resolução do roubo. }\end{array}$ \\
\hline
\end{tabular}

Nesse modelo o papel de João é um dado destacado da situação, cujo significado é o de encaminhar o roubo à polícia e impedir a briga aconselhando Caio. A agressão foi considerada errada. Para o papel da polícia foi atribuído o significado de resolver o roubo e prender o rapaz. $\mathrm{O}$ roubo foi considerado errado. A implicação é a de que João deve impedir a agressão aconselhando Caio, esclarecendo que é errada e encaminhar à polícia a resolução do roubo.

Exemplo de resposta dada com base no modelo 4: Ex.: "O certo é ele apartar a briga, ver o que aconteceu, perguntar e conversar com o amigo. Primeiro se estava tentando roubar mesmo e depois dizer que a briga é errado e chamar a polícia." (RFT, 16 anos e 11 meses).

\section{MODELO 5:}

\begin{tabular}{|l|l|}
\hline Dados abstraídos e retidos como significativos & Significados atribuídos aos dados \\
\hline - Papel do João & - Segurar o rapaz \\
\hline - Papel do Caio & - Chamar a polícia \\
\hline - Papel da polícia & - Prender o rapaz \\
\hline $\begin{array}{l}\text { Implicações e/ou relações entre dados e significados: } \\
\text { João deve impedir o roubo, segurando o rapaz, enquanto Caio chama a polícia } \\
\text { para que o rapaz seja preso. }\end{array}$ \\
\hline
\end{tabular}

9 O dado Papel do Caio, foi considerado como uma ação indireta para a resolução da situação.
Os dados abstraídos foram: papel do João, que significou segurar o rapaz; papel do Caio, que significou chamar a polícia, e o papel da polícia, que teve como significado prender o rapaz. As implicações foram que João deve impedir o roubo, segurando o rapaz, enquanto Caio chama a polícia para que o rapaz seja preso.

Resposta do sujeito que aplicou o modelo 5 na questão 2:

Ex.: "Deveria segurar o cara que tava roubando a moto enquanto o outro chama a polícia." (APS, 17 anos e 10 meses) ${ }^{10}$.

\section{Discussão dos modelos}

Na questão 1 solicitou-se dos participantes um juízo de realidade quando se perguntou o que João pensou da situação. $\mathrm{O}$ resultado dos 20 protocolos de respostas foi uma variedade de modelos e uma extensão de conteúdos. Em todos os cinco modelos apresentados aparecem conteúdos que não figuram no conflito, principalmente relacionados ao papel de João, que passa de observador a ator, e ao papel da polícia, que está ausente na situação narrada, mas tem a função valorizada como útil e positiva nos modelos 3, 4 e 5. A variedade de construções apresentadas pelos sujeitos nos remete à diversidade de representações possíveis em relação à situação apresentada, mesmo tratando-se de um contexto dirigido pela situação de investigação.

Tabela 1. Distribuição do total de participantes que aplicaram cada modelo organizador na questão 1 .

\begin{tabular}{lcccccc}
\hline & Modelo 1 & Modelo 2 & Modelo 3 & Modelo 4 & Modelo 5 & Total \\
\hline $\begin{array}{l}\text { Distribuição } \\
\text { dos Modelos }\end{array}$ & 03 & 04 & 07 & 01 & 05 & 20 \\
& $(15 \%)$ & $(20 \%)$ & $(35 \%)$ & $(5 \%)$ & $(25 \%)$ & $(100 \%)$ \\
\hline
\end{tabular}

O modelo menos aplicado foi o 4 , com $5 \%$ dos participantes (equivalente a 1 participante). Destaca o sentimento de medo que impede João de se envolver diretamente na agressão, solicitando à polícia que resolva da situação. Já $15 \%$ dos participantes aplicaram o modelo 1, que se refere a pensamentos voltados para o comportamento direto de ajuda para com o amigo roubado, agredindo o rapaz transgressor. O modelo 2 foi aplicado por $20 \%$ dos participantes e destaca que João pensou impedir a agressão, em função de benefícios mútuos (de Caio e do rapaz). O modelo 5, que corresponde a $25 \%$, destaca a necessidade de não ferir o rapaz, impedindo a agressão, e de solicitar ajuda da polícia para prendê-lo. Do total de participantes, o mais aplicado (35\%) foi o modelo 3 , cuja idéia destacada

10 Somente uma participante aplicou esse modelo. 
é a de que é a polícia que deve ser acionada para resolver o caso.

A questão 2 se referia a um juízo de valor a respeito da situação de conflito, buscando, desse modo, levantar as representações dos adolescentes sobre ser justo nessa situação. Como na primeira pergunta, observou-se uma variedade de modelos em relação aos 20 protocolos de respostas. Tais ocorrências nos remetem à diversidade de juízos possíveis em relação à situação apresentada. Porém, em todos os modelos, roubo e agressão são considerados errados e o papel de João é solucionar o problema principalmente através da conversa e/ou chamando a polícia. Nos modelos 3, 4 e 5, nos quais aparece, a polícia está valorizada como útil e positiva.

Tabela 2. Distribuição do total de participantes que aplicaram cada modelo organizador na questão 2 .

\begin{tabular}{|c|c|c|c|c|c|c|}
\hline & Modelo 1 & Modelo 2 & Modelo 3 & Modelo 4 & Modelo 5 & Total \\
\hline $\begin{array}{l}\text { Distribuição } \\
\text { dos Modelos }\end{array}$ & $\begin{array}{c}05 \\
(25 \%)\end{array}$ & $\begin{array}{c}05 \\
(25 \%)\end{array}$ & $\begin{array}{c}05 \\
(25 \%)\end{array}$ & $\begin{array}{c}04 \\
(20 \%)\end{array}$ & $\begin{array}{c}01 \\
(5 \%)\end{array}$ & $\begin{array}{c}20 \\
(100 \%)\end{array}$ \\
\hline
\end{tabular}

O modelo menos aplicado foi o 5 , com 5\% de sujeitos (1 participante). Ele implica uma intervenção conjunta do protagonista com Caio e a importância de se encaminhar às autoridades (polícia) o problema do roubo. Em seguida temos o modelo 04 , aplicado por $20 \%$ dos participantes, que considera mais justo aconselhar o amigo a não agredir e encaminhar à polícia a situação do roubo. Com $25 \%$ cada um estão os modelos 1,2 e 3 . O modelo 1 refere-se ao impedimento da agressão através do aconselhamento, o modelo 2 destaca que ser justo é aconselhar, impedir a agressão e conhecer os motivos da necessidade do roubo para se tomarem providências. No modelo 3 a solução justa é encaminhar o problema à polícia.

De modo geral, os modelos revelam que ser justo é resolver o problema não agredindo, conversando e chamando a polícia para resolver a situação.

\section{As categorias}

A diversidade de modelos presentes, tanto na questão 1 quanto na questão 2, reflete as diferenças representativas da situação de conflito proposta. Por outro lado, revela algumas regularidades que demonstram outro aspecto da complexidade presente nos modelos. Para captar melhor esse aspecto das regularidades, identificamos três categorias nas quais se observam pontos comuns entre as implicações das respostas das questões 1 e 2 . Denominamos de categorias A, B e C:

a) os modelos da categoria $A$ centraram as respostas dos adolescentes na participação direta de João (o protagonista) na resolução do roubo, na agressão ou em ambos os problemas; b) os modelos da categoria $B$ destacaram a participação direta de personagens não explicitados no contexto na resolução dos problemas do roubo, da agressão ou em ambos;

c) os modelos da categoria $C$ organizaram suas explicações para a resolução do conflito em torno da participação direta de João em conjunto com outros personagens não explicitados no contexto da situação (por exemplo, a polícia).

Tabela 3. Categorias em que se enquadram os modelos organizadores em relação às questões $1 \mathrm{e} 2$.

\begin{tabular}{lccc}
\hline & Categoria A & Categoria B & Categoria C \\
\cline { 2 - 4 } Questões & \multicolumn{4}{c}{ Modelos } \\
\hline questão 1 & 1 e 2 & 3 e 4 & 5 \\
questão 2 & 1 e 2 & 3 & 4 e 5 \\
\hline
\end{tabular}

Apesar de não termos solicitado dos sujeitos, na questão 1, a necessidade de agir ou dar uma solução para a situação, como foi feito na questão 2 , em todas as implicações existe uma ação (direta e/ou indireta) para resolvê-la, seja sobre o roubo, seja sobre a agressão ou sobre ambos. Essas ações indicam certas regularidades na organização da situação.

Na questão 1 os modelos 1 e 2 buscam a ação do protagonista diretamente na situação (categoria A). Os modelos 3 e 4 buscam personagens que não estão diretamente presentes no conflito para resolver a situação (categoria B). O modelo 5 busca uma ação direta do protagonista e personagens que não estão presentes presentes para resolver o conflito.

Em relação à questão 2, os modelos $1 \mathrm{e} 2$ buscam a ação do protagonista diretamente na situação (categoria A). O modelos 3 busca personagens que não estão diretamente presentes no conflito para resolver a situação (categoria B). Os modelos 4 e 5 buscam uma ação direta do protagonista e personagens que não estão presentes para resolver o conflito (categoria $\mathrm{C}$ ).

No total, dos 10 modelos detectados, 6 (60\%) recorrem a personagens (categorias $\mathrm{B}$ e C) que não estão presentes na situação para resolver os conflitos.

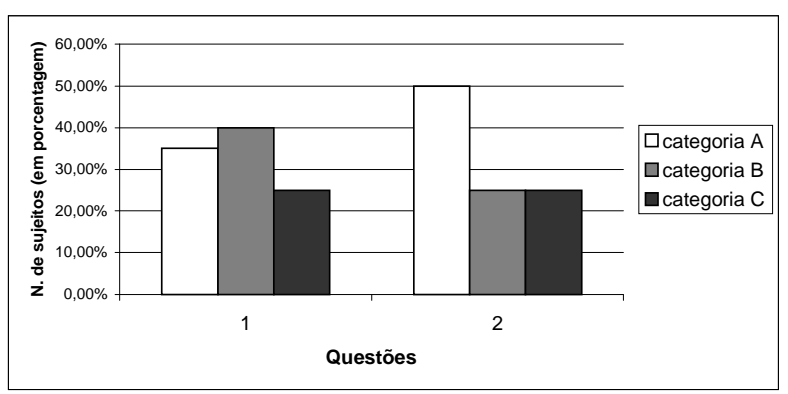

Gráfico 1. Distribuição de sujeitos (em porcentagem) que aplicaram as categorias nas questões 1 e 2 . 
O Gráfico 1 nos informa que, na questão 1 , a categoria B é a mais freqüente, apresentando-se com $40 \%$ (08) de sujeitos que a aplicaram. Em seguida vem a categoria $\mathrm{A}$, com $35 \%(07)$ de freqüência de aplicação, e a categoria C, com $25 \%$ (05). Portanto, na questão 1 , existe o predomínio da aplicação de modelos organizadores que sistematizam a resolução da situação com base em personagens ausentes. Isso significa que, no juízo de realidade, esteve presente, por exemplo, ao incumbirem a resolução do problema do roubo à polícia, o reconhecimento dessa instituição como instância para a solução desse tipo de problema.

Na questão 2, a categoria A é predominante, com $50 \%$ (10) do total de sujeitos, na qual estes pautaram suas explicações sobre a resolução do conflito na ação direta do protagonista João. Torna-se importante lembrar que, no caso da questão 2 , a ação de João já estava explícita no enunciado da questão. Todavia, observamos que, mesmo assim, os outros $50 \%$ dos adolescentes (05 da categoria B e 05 da categoria C) abstraíram dados não explícitos no enunciado da questão e nem diretamente no contexto (polícia), articulando-os (no caso da categoria C) com dados do enunciado (João).

Verificamos também a variação intrapessoal na aplicação das categorias para detectar se os sujeitos mudavam ou não a aplicação de categorias de modelos em função da natureza da questão apresentada (1 e 2 ). A análise da variação interpessoal pode auxiliar na compreensão do funcionamento cognitivo dos sujeitos, quando aplicam diferentes tipos ou o mesmo tipo de categoria de modelos organizadores para resolver uma situação de conflito; isto é, pode nos fornecer indícios sobre a diversidade de estratégias cognitivas, apontando se há diversidade ou continuidade/regularidade da perspectiva de raciocínio em função das questões colocadas sobre a mesma situação.

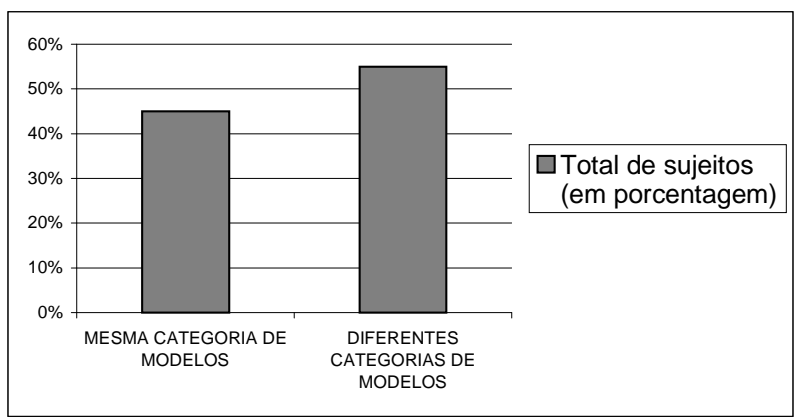

Gráfico 2. Distribuição de sujeitos (em porcentagem) que aplicaram nas questões 1 e 2 a mesma categoria e diferentes categorias.

O gráfico 2 informa que a mesma categoria de modelos organizadores (por exemplo A e A) foi aplicada por 45\% (09) dos sujeitos da amostra nas questões 1 e 2, demonstrando certa regularidade na perspectiva de raciocínio. Por outro lado, 55\% (11) aplicaram categorias diferentes. Nesse caso, os sujeitos apresentaram raciocínio diverso para as diferentes questões.

\section{CONCLUSÃO}

Conclui-se, a partir dos resultados dessa investigação, que diferentes modelos foram utilizados na resolução da situação apresentada aos adolescentes. Percebeu-se, também, que os conteúdos dos modelos estenderam-se para além dos elementos presentes no conflito narrado, com vários sujeitos recorrendo às necessidades dos personagens, às leis, a figuras de autoridade, às normas sociais e regras de relacionamento interpessoal. A interpretação da realidade dependeu do sistema de inferências do participante. Mesmo sem ser solicitados (como na questão 1), os participantes recorreram a ações e juízos de valor moral para solucionar o conflito narrado. Tal fato nos leva a refletir sobre as relações entre representação e ação, e reitera a importância do pressuposto de que os modelos de um sujeito servem de ponto de partida para a ação, já que esta não tem como base a realidade, mas o que cada um acredita ser a realidade (Moreno \& col., 1999). Conhecer os modelos inferidos pelos sujeitos nos aproxima de suas ações e/ou, no mínimo, das explicações para suas ações.

Os raciocínios dos adolescentes também mostraram regularidades na resolução da situação de conflito. Esse fato está demonstrado nas categorias A, B e C. Desse modo, apesar da diversidade dos modelos, existe regularidade na argumentação dos sujeitos sobre as resoluções possíveis para a situação. Mesmo sendo distintas as duas questões propostas (uma a partir de um juízo de realidade e outra a partir do juízo de valor), a construção dessas categorias emergiu em função da continuidade de princípios que orientaram os raciocínios dos adolescentes: a busca da resolução da situação por parte de personagens explícitos e/ou não explícitos no contexto. Como vimos, $40 \%$ (quarenta por cento) dos modelos estão inclusos na categoria $\mathrm{A}$, que expressa uma ação direta do protagonista, e 60\% (sessenta por cento) dos modelos estão inclusos em categorias (B e C) que recorrem a outros personagens. Isso revela que, na maioria das vezes, a representação dos participantes não foi imediatista e centralizadora, mas, sim, recorrente a conteúdos exteriores. Pudemos visualizar, também, a integração de perspectivas, como a 
expressa pela Categoria $\mathrm{C}$, que leva em consideração diversos aspectos para resolver a situação de conflito: as necessidades dos personagens da situação, as expectativas em relação às autoridades e direitos e deveres estabelecidos pela sociedade.

A definição das categorias nos permitiu verificar um aspecto que estava além de nossos objetivos, mas que é extremamente relevante no contexto da realidade que envolve adolescentes infratores e traz implicações para as ações desenvolvidas pelas instituições que cuidam dessa população. Desde há muito tempo (Vasconcelos, 1985), observamos que no discurso generalizado dessas instituições está presente a afirmação de que os adolescentes infratores não pensam nas conseqüências do roubo e agressão, são centralizadores, imediatistas e não consideram relevantes figuras de autoridade. Por isso, agentes institucionais consideram que as ações educativas dirigidas a essa clientela são "perda de tempo". Porém, as categorias abstraídas nessa pesquisa permitem observar de forma transparente que muitos julgamentos dos adolescentes caminham exatamente no sentido contrário da percepção generalizada dos agentes institucionais. Constatamos que a agressão e o roubo são comportamentos condenáveis na maior parte dos modelos, mas considerados eventualmente " necessários", diante de uma situação real. Tal fato indica que regras sociais mais gerais são internalizadas pelos adolescentes, mas relativizadas na ação, dependendo das contingências e necessidades do sujeito. Portanto, os modelos construídos pelos participantes indicam que seus julgamentos nem sempre são centralizadores, pois na maioria das situações recorrem a personagens que não estão presentes no conflito para solucioná-lo; consideram as conseqüências dos atos, pois afirmam que roubo e agressão são "errados" e que podem produzir conseqüências; relevam as figuras de autoridade, pois em $60 \%$ dos modelos (3 na questão A e 3 na questão B) incluem a polícia como personagem para solucionar o caso.

Tais resultados revelam que estigmas e mitos compõem a realidade institucional dos adolescentes infratores. Cada vez mais, observamos que a inferência ideológica generalizada de agentes institucionais de que "pau que nasce torto, não tem jeito, morre torto" não está de acordo com os resultados obtidos nas investigações. Pensamos que precisamos promover mudanças no âmbito das medidas socioeducativas desses adolescentes, tanto em meio aberto (Liberdade Assistida e Prestação de Serviços à Comunidade) quanto em ambiente fechado (Internação). Além dos procedimentos usuais, que são o aconselhamento e orientação, poderiam ser implementadas outras atividades, voltadas para reflexão e ação sobre temas morais, envolvendo adolescentes e agentes institucionais. Sob a forma de oficinas e atividades em grupos poder-se-iam construir espaços de reflexão e ação em que fossem abarcados diversos aspectos de conflitos das relações sociais humanas: valores, sentimentos, regras e princípios que constituem a complexidade da realidade em que vivemos; enfim, um contexto no qual se pudesse promover a reflexão e a ação, permitindo aos adolescentes conhecer-se, interpretar situações e situar-se em seu cotidiano.

Finalmente, os resultados desta pesquisa apontam para a necessidade de ampliação de investigações envolvendo ação e juízo moral, para que possamos compreender melhor por que esses adolescentes pensam de uma maneira e agem de outra forma. É preciso ampliar o conceito de juízo moral para além do modelo estrutural em vigor na psicologia, explorando mais profundamente as relações entre estruturas e conteúdos.

Estudar os raciocínios dos adolescentes que participaram dessa pesquisa, sem dúvida, nos permitiu perceber que valores, sentimentos e princípios diversos estão em jogo nos modelos que organizam o pensamento na resolução de conflitos morais. Pudemos conhecer melhor a diversidade $\mathrm{e}$ as regularidades que compõem as complexas representações que fazem parte da realidade desses sujeitos. Os modelos detectados também sugerem que uma reflexão mais ampla sobre o conceito de moralidade deve adentrar no campo educacional, superando a idéia de que a educação moral é aquela que se volta exclusivamente para o desenvolvimento de deveres cívicos. Essa discussão já foi recomendada por Puig (1998), para quem o objetivo da educação moral deveria ser a construção de personalidades morais e, Sastre e Moreno (2002), que alertam para a premência de se pensar em um novo contexto educacional onde se possa refletir sobre as interrelações entre razão e emoção. Quem sabe venhamos a poder, desse modo, fomentar o desenvolvimento de seres humanos com a sensibilidade necessária para resolver conflitos e viver democraticamente em sociedade.

\section{REFERÊNCIAS}

Adorno, S. P. (2000) Adolescentes, crime e violência. Em H. W. Abramo, M. V. Freitas, \& M. P. Sposito (Org.), Juventude em debate (pp.97-109). São Paulo: Cortez/Ação Educativa 
Al-Falai, J. (1992) Family conditions, ego development and sociomoral development in juvenile delinquency: a study of bahraini adolescents. Dissertation Abstracts International, 52 (12-A), 4224-4225.

Arantes, V. A. (2000) Cognição, afetividade e moralidade. Educação e Pesquisa, 26 (2), 137-153.

Associação Brasileira dos Institutos de Pesquisa de Mercado. (1978) Proposição para um novo critério de classificação sócio-econômica. São Paulo.

Blasi, A. (1995) Moral understanding an the moral personality: the process of moral integration. In W. Kurtines \& J. Gerwitz, Moral Development:introduction. Boston: Ally and Bacon.

Bzuneck, J. A. (1979) Julgamento moral de adolescentes delinqüentes e não-delinqüentes em relação à ausência paterna. Tese de Doutorado, Universidade de São Paulo, São Paulo.

Carlo, G., Eisenberg, N. E. \& Koller, S. H. (1998) Prosocial moral reasoning in institucionalized delinquent, orphaned, and non-institucionalized brazilian adolescents. Journal of Adolescents Research, 13 (4), 363-76.

Conselho Regional de Psicologia 6 ${ }^{\mathrm{a}}$ Região (1999, Novembro/Dezembro) FEBEM : mal estar nacional. PSI Jornal do CRP-SP, p. 6-8.

Damon, W. (1995) Greater expectations. San Francisco: The Free Press.

Eisenberg, N. (1979) Development of prosocial moral judgement and its contents. Developmental Psychology, 15, 128-137.

Gilligan, C. (1993) Uma voz diferente: psicologia da diferença entre homens e mulheres da infância à idade adulta. Rio de Janeiro: Editora Rosa dos Ventos.

Guará, I. S. (2000) O crime não compensa mas não admite falhas: padrões morais em jovens autores de infração. Tese de Doutorado, Pontifícia Universidade Católica de São Paulo, São Paulo.

Koller, S. H. (1989) Diferenças entre o nível de julgamento moral de adolescentes infratores e não-infratores. Estudos de Psicologia, 6 (1), 127-134.

Menin, M. S. (2000) Representações sociais de justiça em adolescentes infratores: discutindo novas possibilidades de pesquisa. Revista Psicologia: Reflexão $e$ Crítica,13(1).Disponível em: <http.//www.scielo.br/>. (Acessado em: 03/02/2001).
Moreno M., Sastre, G., Leal A. \& Bovet M.(1999) Conhecimento e mudança: os modelos organizadores na construção do conhecimento. Campinas/ São Paulo: Editora da Unicamp/Editora Moderna.

Morin, E. (2000) Ciência com consciência. Rio de Janeiro: Bertrand Brasil.

Oliveira, C. A. A. \& Costa, A. E. B. da. (1995) Os dilemas morais e não-morais no cotidiano de conflitos de adolescentes de Minas Gerais. Revista Psicologia: Reflexão e Crítica, 8(1),73-90.

Oliveira, C. A. A. \& Costa, A. E. B. (1997) Categorias de conflitos no cotidiano de adolescentes mineiros. Revista Psicologia: Reflexão e Crítica, 10 (1).Disponível em: <http://www.scielo.br/>. (Acessado em: 20/10/2001).

Puig, J. M. (1998) A construção da personalidade moral. São Paulo: Ática.

Sastre, G. \& Moreno M. (2000) Nuevas perspectivas sobre el razionamiento moral. Educação e Pesquisa, 26(2),123-125.

Sastre, G. \& Moreno, M.(2002) Resolución de conflictos y aprendizage emcional: una perpectiva de género. Barcelona: Gedisa Editoria.

Tiba, I. (1986) Puberdade e adolescência: desenvolvimento biopsicossocial. São Paulo: Ágora.

Trevisol, M. T. C. (2002) A construção do conhecimento social: um estudo dos modelos organizadores do pensamento em sujeitos entre 8 e 14 anos. Tese de Doutorado, Universidade de São Paulo, São Paulo.

Vasconcelos, M. S. (Org.) (1997). Criatividade: psicologia, educação e conhecimento do novo. São Paulo: Moderna.

Vasconcelos, M. S. (1985) Reintegração familiar do menor: meta ou mito. Dissertação de Mestrado, Pontifícia Universidade Católica de São Paulo, São Paulo.

Volpi, M. (Org.) (1999) O adolescente e o ato infracional. São Paulo: Cortez.

Endereço para correspondência: Leonardo Lemos de Souza, Universidade Paulista-Unip, Rua Myrthes Spera Conceição, 301, Cep 19800-000 - Assis - SP. E-mail: 1lsouza@ hotmail.com ou 